New Zealand. D. antarctica is known from Valparaiso to Cape Horn and up to about $50^{\circ} \mathrm{S}$. lat. on the east coast of South America, from the Strait of Magellan, from the Falkland Islands, from drift (but $n \cdot t$ certainly growing) at South Georgia, and from Kerguelen ${ }^{2}$; it is abundant in suitable habitats around the coast of New Zealand and its outlying islands. The central layers of its divided leathery blade are occupied by a series of air-chambers so that the fronds float on the surface of the extremely turbulent waters where this species characteristically grows. Skottsberg ${ }^{3}$, referring to fragments of $D$. antarctica cast ashore on Deception Island where it has not been found growing, says that they may have been carried down from Fuegia during northwest gales, or have come from New Zealand with the west-wind drift. The three new records suggest that $D$. antarctica may yet be found growing on out-of-theway parts of the Australian coast, although it is quite possible that the pieces found had floated very long distances. The nearest source to the west is Kerguelen, more than five thousand miles away.

Botany Division,

Department of Scientific

and Industrial Research,

Wellington, New Zealand.

Department of Botany,

University of Queensland,

Brisbane, Queensland. May 2.

1 Lindauer, V. W., Pac. Sci., 3, 348 (1949).

"Skottsberg, C., "Wissensch. Firgebn. der schwed. Südpolar-Expedition 1901

s Skottsberg, C. K., Svensk. Vetensk. Bandl., 3rd Ser., 19 (4), 48 (1941).

\section{Autolysis of Flight Muscles in a Mosquito}

DURING July 1951 a number of specimens of gravid female mosquitoes, in which the flight muscles showed various degrees of autolysis, were collected in the vicinity of Churchill, Manitoba. The loss of scales and hairs renders identification of a mosquito of this group impossible by means of conventional characters. There is good circumstantial evidence, however, that all these specimens were either Aedes communis De Geer, or an as yet undescribed species indistinguishable from it on any single morphological character in the larval or adult stage ${ }^{1}$.

Whatever its identity, in this area at least, it is doubtful if this species ever takes a blood meal. About twenty specimens were examined, and there was good inverse agreement between the degree of egg development and the degree of breakdown of flight muscle. Specimens in which the eggs were almost ready to be laid showed no trace of either tergo-sternal or dorsal flight muscles, the mesothorax thus appearing almost completely devoid of solid structures. The number of eggs developed ranged from 43 to 91 , with an average of 64 . All specimens were taken by sweeping with a heavy net in vegetation close to the ground, and most of them not far from the margins of pools in which the larvæ of these species develop.

It seems clear that this species must become a flightless insect very soon after egg development commences. This would explain the failure to capture gravid females in the field in previous seasons. It also agrees well with the observations of
Jenkins and Hassett ${ }^{2}$ indicating a very limited dispersal range for this species complex. Preliminary observations suggest that the nitrogen content of the flight muscles is roughly equivalent to that of about sixty eggs, and it appears unquestionable that this represents a parallel to the situation reported in ants by Wheeler ${ }^{3}$, the nitrogen of the flight muscles being utilized in the production of eggs. A fuller account of these observations will be published elsewhere.

I am indebted to Mr. G. S. Eligh, Division of Entomology, Department of Agriculture, Kingston, Ontario, who brought in the first specimens, taken during a search at Churchill, Manitoba, for bloodengorged females, and to the Canadian Defence Research Board, Ottawa, and the Division of Entomology, Ottawa, which provided the opportunity for this material to be studied.

Department of Entomology,

B. HockING

University of Alberta, Edmonton.

Dec. 4.

${ }^{1}$ Hocking, B., Richards, W. R., and T'winn, C. R., Can. J. Res., D, 28, 58 (1950).

$2 J$ Jenkins, D. W., and Hassett, C. C., Can. J. Zool., 29, 178 (1951). 3. Wheeler, W. M., "The Social Insects", 169 (Kegan Paul, London,
1928).

\section{The Bent Excited State of Acetylene}

THE band systems of $\mathrm{C}_{2} \mathrm{H}_{2}$ and $\mathrm{C}_{2} \mathrm{D}_{2}$ at 2400 $2100 \mathrm{~A}$. have been studied in absorption, and the vibrational and resolved rotational structures fully analysed. It emerges that, in its excited state, acetylene is a plane centrosymmetric zig-zag (like ethylene from which two trans-related hydrogen atoms have been removed). It is therefore an asymmetric top. Its dimensions in the lowest vibrational level of that state are $\mathrm{CC}=1.383 \mathrm{~A}$., $\mathrm{CH}=1.08 \mathrm{~A}$., $\angle \mathrm{CCH}=$ $120 \cdot 2^{\circ}$. The frequency of the $\mathrm{CC}$ stretching vibration is $1,385 \mathrm{~cm}^{-1}$ in $\mathrm{C}_{2} \mathrm{H}_{2}$ and $1,300 \mathrm{~cm} .^{-1}$ in $\mathrm{C}_{2} \mathrm{D}_{2}$, the derived mean force-constant being $F=7 \cdot 2 \times 10^{5}$ dyne/cm.; while the vibration which together opens the angles has the frequency $1,049 \mathrm{~cm}^{-1}$ in $\mathrm{C}_{2} \mathrm{H}_{2}$ and $835 \mathrm{~cm}^{-1}$ in $\mathrm{C}_{2} \mathrm{D}_{2}$, the corresponding mean bendingforce-constant being $\delta=8.5 \times 10^{-12}$ dyne.-cm. radian. The electronic wave function has the two-fold axis and plane, but not the centre of symmetry of the zig-zag molecule. The lowest vibrational level of this bent excited state lies at $42,209 \mathrm{~cm}^{-1}$ in $\mathrm{C}_{2} \mathrm{H}_{2}$ and at $42,280 \mathrm{~cm} .^{-1}$ in $\mathrm{C}_{2} \mathrm{D}_{2}$, above that of the linear normal state, the difference of $71 \mathrm{~cm}^{-1}$ arising from differences in zero-point vibrational energy. In the transition from the normal to the excited state, the electrons oscillate perpendicularly to the plane of the bent molecule. The resultant electron-spin remains zero. The transition probability, expressed as an oscillator strength, is $8 \times 10^{-5}$. All this follows from the analysis of the spectra.

Molecular orbital theory indicates that the lowest electronically excited state to which transition is allowed should be of the described symmetry. The $\sigma$-bond hybridization is plane-trigonal (as in ethylene or benzene), and there is otherwise one $\pi$-orbital in the CC-bond for shared electrons, and one nonbonding orbital on each carbon atom for unshared electrons, not to mention many more highly energized orbitals. After the completion of the $\sigma$-bond system, four electrons remain, which are insufficient to fill the $\pi$-bonding and the two non-bonding orbitals up to the limit allowed by the Pauli principle. In the 